
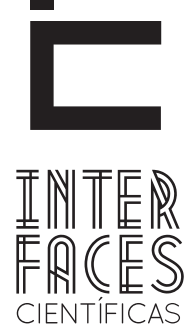

EDUCAÇÃO

\title{
FORMAÇÃO DOCENTE E EDUCACÃO INCLUSIVA: UMA ANÁLISE PSICOPEDAGÓGICA
}

\section{RESUMO}

O artigo aborda a política pública de educação inclusiva implementada no Brasil nos últimos anos, sob a égide da exclusão. 0 recorte da investigação alcança aspectos emergentes das interações gestor - professor - aluno - pais - conhecimento com foco na educação básica de pessoas com deficiência (s), em instituições de Educação Especial e de Educação Inclusiva, públicas e particulares, no período de 2002 a 2004, com suas implicações na formação de professor. Nas instituições identifica a convivência de estigmas, mecanismos de defesa e preconceitos, com marco teórico fundado em Freud (1995), Gay (1999), Amaral (1994) e Goffman (1988). Conclui denunciando a manipulação, o domínio das institui- ções que detêm o poder com padrões de normalidade e indicando a necessidade da ação organizada da sociedade civil para retomar o controle dessas práticas, cobrando a aplicação das políticas inclusivas, radicalizando seus próprios discursos. Trata da condição humana, da luta concreta pela superação da cultura do sofrimento em favor da felicidade de cada homem.

\section{PALAVRAS-CHAVE}

Educação Especial. Educação Inclusiva. Estigmas. Mecanismos de Defesa. Preconceitos. 


\section{ABSTRACT}

The article discusses the public policy of inclusive education implemented in Brazil in recent years, under the aegis of exclusion. The clipping of the investigation reaches emerging aspects of interactions manager - teacher - student - parents - knowledge focusing on basic education of persons with disability(s) in institutions of Special Education and Inclusive Education, public and private, in the period from 2002 to 2004, with implications for teacher training. In institutions identifies the coexistence of stigmas, prejudices and defense mechanisms, with a theoretical framework founded on Freud (1995), Gay (1999), Amaral (1994) and Goffman (1988). Concludes denouncing the manipulation, the domain of institutions that hold power with normal standards and indicating the need for organized civil society action to regain control of these practices, demanding the implementation of inclusive policies, radicalizing his own speeches. This is the human condition, the concrete struggle for overcoming the culture of suffering in favor of happiness of each man.

\section{KEY WORDS}

Special Education. Inclusive Education. Stigmata. Defense mechanisms. Prejudices.

\section{INTRODUÇ̄̃O}

Este artigo é fruto de pesquisas e reflexões desenvolvidas por uma pedagoga e uma psicóloga do Grupo de Pesquisa em Políticas Públicas, Gestão Socioeducacional e Formação de Professor da Universidade Tiradentes - Sergipe, ambas com experiência na educação básica e na educação superior, inclusive com atuação junto à Educação Especial em secretarias de educação (estadual e municipal).

\section{RESUMEN}

El artículo analiza la política pública de educación inclusiva aplicada en Brasil en los últimos años, bajo la égida de la exclusión. El recorte de la investigación alcanza aspectos emergentes de las interacciones director - profesor - alumno - padres - conocimiento con énfasis en la educación básica de personas con discapacidad (es) en instituciones de Educación Especial y de Educación Inclusiva, públicas y privadas, en el período de 2002 a 2004, con sus implicaciones en la formación del profesor. En las instituciones identifica la coexistencia de estigmas, prejuicios y mecanismos de defensa, con un marco teórico fundado en Freud (1995), Gay (1999), Amaral (1994) y Goffman (1988). Concluye denunciando la manipulación, el dominio de las instituciones que detienen el poder con los estándares de normalidad, lo que indica la necesidad de una acción organizada de la sociedad civil para recuperar el control de esas prácticas, exigiendo la implementación de políticas inclusivas, radicalizando sus propios discursos. Trata de la condición humana, de la lucha concreta para superación de la cultura del sufrimiento en favor de la felicidad de cada hombre.

\section{PALABRAS CLAVE}

Educación Especial. Educación Inclusiva. Estigmas. Mecanismos de Defensa. Prejuicios.

A temática abordada é a política pública de educação inclusiva implementada pelo Estado Brasileiro nos últimos anos, mantidas as relações sociais instaladas sob a égide da exclusão. 0 recorte da investigação alcança aspectos emergentes das interações gestor - professor - aluno - pais - conhecimento, com foco na educação básica de pessoas com deficiência (s), em instituições de Educação 
Especial e de Educação Inclusiva, públicas e particulares, no período de 2002 a 2004. Situamo-nos aqui no espaço intraescolar por considerá-lo lócus privilegiado na busca de indicadores da efetividade dessa política pública, com suas implicações na formação de professor.

Desde os anos noventa do século XX, os movimentos sociais têm reivindicado direitos e assegurado conquistas no combate às discriminações nas áreas da saúde, do trabalho, da educação - em especial de grupos excluídos historicamente, como negros, índios, mulheres, alunos de escola pública e pessoas com deficiência, dentre outros - desencadeando debates cada vez mais amplos sobre políticas inclusivas e ações afirmativas.

Sob o ponto de vista da sociologia da educação, podemos afirmar que não houve mudança nas duas últimas décadas em relação à educação, entendida como amplo e contínuo processo de socialização da cultura historicamente acumulada e como desenvolvimento do potencial de seus cidadãos. Castro (2009) demonstra que nessas décadas deu-se apenas a ampliação do acesso da população à parte da educação infantil, contemplando as pré-escolas e, não na mesma progressão, as creches. Ocorreu a universalização do acesso ao ensino fundamental, sem repercussão na superação das desigualdades sociais instaladas, da insuficiência e desigualdade de desempenho, que permanecem interferindo na conclusão do ensino fundamental e do médio, portanto, da educação básica, continuando problemático o acesso ao ensino médio e à educação superior (ainda privilégios de poucos). Acirraram-se as desigualdades regionais, onerando drasticamente 0 Nordeste e os segmentos mais pobres da população. Trata-se assim de uma permanente desigualdade que está, ao longo dos anos, a plasmar o contexto da educação brasileira e a cobrar a responsabilidade, primeiramente, do poder público, mas também da sociedade em geral e de cada um dos cidadãos em particular.
O norte deste artigo é a crença na função social da escola que, embora reproduza concepções vigentes, é capaz de, pela mediação dos profissionais da educação, contribuir para a transformação social. Por essa razão, sua trajetória teórico-metodológica tem como ponto de partida uma discussão da amplitude da política de inclusão em relação aos diversos grupos excluídos, apresentando em seguida uma pesquisa de campo, de natureza qualitativa, descritiva, realizada em instituições educacionais que atuam na educação básica de pessoas com deficiência (s), setor que, contraditoriamente, tem gerado muita polêmica e resistência em relação à inclusão.

O objetivo da investigação é caracterizar como as instituições educacionais (in) viabilizam a política de inclusão através de relações de convivência entre alunos com e sem deficiência (s) e de que forma gestores, professores e pais interagem e vivenciam a segregação e/ou a inclusão. Após revisão da literatura, observações e entrevistas realizadas no período de 2002 a 2004, reconstruímos categorias de análise, como: estigmas, preconceitos e mecanismos de defesa (negação, superproteção e projeção), que emergem como resistência nas relações interpessoais entre os ditos "normais" em relação às pessoas com deficiência (s).

Justificamos o foco nas instituições por reconhecermos que são elas que acionam e controlam o indivíduo em sociedade, determinando-o, delimitando-o, incluindo-o ou excluindo-o, razão pela qual contemplamos escolas com propostas segregativas e/ou inclusivas voltadas à educação de pessoas com deficiência (s), em uma das capitais do nordeste do país, vanguarda do movimento inclusivo, não identificadas neste artigo. Dentro de cada instituição, foram entrevistados e observados alunos com e sem deficiência (s), diretores, professores e pais de alunos, o que desvelou o controle que aciona as regras, normas e valores de condutas, na sua maioria estereotipada a partir de preconceitos, estigmas e mecanismos de defesa. 
A tese aqui defendida é que somos, todos, pessoas muito especiais e que a substantiva política de inclusão educacional haverá de contemplar todos os cidadãos, penetrar todas as salas de aulas e alcançar cada criança, pré-adolescente, adolescente, jovem, adulto e idoso, com a ampla e eficaz socialização da cultura, independentemente das diferenças que assinalam a condição humana e daquelas impostas pelo modo concreto de produção da existência dos sujeitos.

\section{CONVIVÊNCIA COM ESTIGMAS, MECANISMOS DE DEFESA E PRECONCEITOS NAS INSTITUICÕES}

No percurso da investigação teórica houve a necessidade de uma abordagem sobre o funcionamento das instituições frente às relações vivenciadas no âmbito da educação inclusiva. Tornou-se imprescindível uma ampla compreensão de como se estruturou a sociedade, sob o olhar psicanalítico. A psicanálise nos convida a observar as origens da civilização e o caminho que ela desenvolveu, indagando qual a trilha que nos resta, a exemplo de Freud (1927).

No processo de desenvolvimento da civilização, foi imposta ao homem a renúncia ao princípio do prazer para que assim houvesse produção. Os instintos de autopreservação do ego, princípio de realidade, substituem o princípio do prazer, embora o princípio do prazer não abandone o objetivo de satisfação. 0 que ocorre é um adiamento da satisfação e a tolerância por esse adiamento, pelo desprazer, como uma fase no percurso para se chegar ao prazer. Adia-se o prazer em prol da vida em sociedade, abre-se mão dos instintos para que assim possa emergir a cultura, a ordem, as instituições. Assim, implanta-se a ordem como função de facilitação da vida em comunidade e para proteger-se contra os impulsos hostis dos homens, uma vez que estes podem destruir as criações humanas, tudo que foi criado pela tecnologia, pela ciência e utilizá-las para o seu próprio aniquilamento. 0 homem não consegue viver isolado e a vida em sociedade lhe cobra pesado fardo, como demonstra Freud (1927), em detrimento do propósito de feli- cidade, que seria a falta de sofrimento. Esse é o desconforto do impasse da civilização, gerador de neuroses: abolição da felicidade exigida, em favor da sociedade em prol dos ideais da cultura. Explica Freud (1930, p.84):

Como vemos, o que decide o propósito da vida é simplesmente o programa do princípio do prazer. Esse princípio domina o funcionamento do aparelho psíquico desde o início. Não pode haver dúvida sobre a eficácia, ainda que seu programa encontre em desacordo com o mundo inteiro, tanto com o macrocosmo quanto com o microcosmo. Não há possibilidade alguma de ele ser executado, todas as normas do universo são-lhe contrárias. Ficamos inclinados a dizer que a intenção de que o homem seja feliz não se acha incluída no plano da criação.

Nesse sentido, os neuróticos, por não tolerarem a frustração imposta pela sociedade, buscam formas de satisfações substitutivas para si que resultam em sofrimentos, dificuldades e mal-estar nos relacionamentos; para se proteger do sofrimento que pode emergir dos relacionamentos humanos, a medida de defesa é o isolamento; afastam-se das pessoas; distanciando-se, criando barreiras. A civilização acaba por ser resultante das imperfeições, das maneiras culturais que foram desenvolvidas, da exploração de uma minoria sobre uma maioria. "Fica-se assim com a impressão de que a civilização é algo que foi imposto a uma maioria resistente por uma minoria que compreendeu como obter posse dos meios de poder e coerção [...]" (FREUD,1927, p. 16). 
Comungamos do questionamento de Freud (1921) sobre o que mantém o elo entre os membros de um grupo, além do racional interesse próprio. A resposta encontra-se na psicologia social uma vez que, na vida mental do indivíduo, o Outro entra como ideal, objeto, auxiliar e adversário. Este Outro é instaurado a partir da estrutura mental do indivíduo, no desenvolvimento da personalidade. 0 indivíduo tem a necessidade de direcionar sempre as atitudes para um outro que se encontra instaurado em sua realidade psíquica. Assim, trabalhar com a psicologia individual implica a psicologia social. A psicanálise nos ensina que, desde o nascimento, a criança fica exposta a uma série de influências de todas as pessoas à sua volta, que se ampliam e diversificam durante a infância. À medida que ela vai-se desenvolvendo, fica sujeita à modelação por meio do encorajamento e da desvalorização, do elogio e da censura, do exemplo invejável ou desagradável dos outros. 0 desenvolvimento da personalidade, os sintomas neuróticos e os conflitos centrados nos sentimentos de amor e de ódio resultam de formações de compromisso entre impulsos internos e pressões externas.

Torna-se impossível pesquisar a vida interior sem recorrer ao mundo externo, uma vez que ao estudarmos a vida mental do sujeito há sempre algo mais inserido: um modelo, um objeto. Os fenômenos sociais emergem desde o início nas relações do sujeito estabelecidas com os pais e irmãos. Essas relações consolidadas justificarão as transferências que depositaremos na convivência com outras pessoas durante toda a vida.

O processo mental consciente atua como resultante do nosso inconsciente, que acaba por comandar as nossas ações, o tempo todo. Temos assim o procedimento de nossas ações, atitudes e, por detrás dessas causas secretas, existem outras mais secretas ainda que fogem à nossa observação. Os grupos unem-se através das relações transferenciais imbuídas de identificação, carregadas de um elo emocional, resultados de um modelo que se originou na infância. Nas rela- ções emerge a figura dos líderes; formam-se grupos que, sob a influência de um líder, são capazes de elevadas realizações, construções, desprendimento e devoção a um ideal. Quando esse elo emocional afrouxa, surge a desintegração dos grupos. (GAY, 1999, p. 371)

No processo de desenvolvimento da história da civilização, destaca-se a exploração do trabalho sob o lema da coerção. 0 resultado tem sido a revolta, a indignação dos grupos pelo grau de insatisfação sofrida, gerada pelas intensas explorações do trabalho humano sem a mínima satisfação, resultando assim os defeitos nos regulamentos culturais, falhas, levando a uma sociedade amargurada, vingativa e inacessível. É de se esperar que essas classes oprimidas desenvolvam uma intensa hostilidade para com a sociedade. Com um número tão grande de participantes insatisfeitos, a revolta para a libertação da exploração imposta por uma minoria é a resposta esperada, talvez pela via da tecnologia, como analisa Gay (1999).

Por certo, gostaríamos de ver surgir uma sociedade mais justa, com gerações novas, líderes desinteressados, atuando como educadores das gerações futuras, de importância indiscutível para a sociedade humana. Entendemos que a educação do futuro deve promover a inteligência, utilizar os conhecimentos existentes e identificar as falsas racionalidades. Concordamos com Morin (2001) quando propõe o favorecimento da aptidão natural da mente em formular e resolver problemas essenciais, estimulando e despertando o livre exercício da curiosidade, que se encontra mais expandida e mais viva durante a infância, adolescência e que, frequentemente, é extinta pela instrução.

A segregação na educação escolar das pessoas com deficiência (s) vem sendo praticada há séculos pelas instituições. Há atitudes políticas sedimentadas no controle dessa questão que resistem ao ensino inclusivo e que persistem na vivência segregativa das pessoas com deficiência (s). Na análise do percurso da educação especial, verificamos a emergência de uma preocupação de parte dos governantes, provo- 
cada por pais e educadores da área, sobre a inserção das pessoas com deficiência (s), uma vez que acreditavam que elas careciam de potencial acadêmico para desenvolverem-se, embora possuidoras de uma moral subversiva que cria sérios obstáculos ao desenvolvimento do ensino regular.

Surge, assim, o ensino segregado da educação especial: seja através de instituições de educação especial seja via classes especiais, com altos investimentos na especialização de professores para atender unicamente a esse segmento da população. Os professores do ensino regular não se acham capacitados para atender alunos com deficiência (s). Foi assim que emergiu a educação especial, não por razões humanitárias, mas baseada no controle e fundada no objetivo de garantir que as pessoas com deficiência (s), vistas como indivíduos com influências subversivas, fossem contidas e indesejadas nas salas de aulas do ensino regular.

Ainda hoje verificamos a dificuldade de superação, o que nos permite falar de uma resistência ao ensino inclusivo, comprovado pela desproporção entre o aumento acentuado de crianças identificadas como pessoas com "deficiência" no seu dia a dia e o aumento mínimo de pessoas com deficiência (s) que são encaminhadas ao ensino inclusivo. Também constatamos atualmente ações de instituições educacionais que se declaram inclusivas e, na prática, voltam-se para o controle e a estigmatização das pessoas com deficiência (s). A escola, como instituição social, tem progressivamente tentado enquadrar cada indivíduo às necessidades da sociedade, estabelecendo quais os alunos que the interessam e praticado a inclusão e/ou a exclusão, intensificando a estruturação do exercício das inteligências e estimulando a competitividade com o objetivo de inserir cada indivíduo nas diversas funções de prestações de serviços úteis à ordem socioeconômica estabelecida. Trata-se do arbítrio sobre vidas: quais as que são dignas de serem vividas nesta sociedade?
A inclusão de que falamos implica mais que a fusão do ensino regular com o especial; não é junção, justaposição ou agregação de uma modalidade à outra, até porque a escola regular é excludente também com os alunos ditos normais, porque os preconceitos são muitos e não se limitam às pessoas com deficiência (s). Falamos de algo mais que o processo de fundir, esse que, por si, já significaria incorporar elementos distintos para se criar uma nova estrutura, na qual são extintos os elementos iniciais. Não podemos continuar a ignorar os efeitos da segregação. Em uma sociedade cada vez mais diversificada, a vivência inclusiva forma os alunos para a convivência com os outros, todos diferentes uns dos outros, inclusive alguns com deficiência (s). Segregar os alunos com deficiência (s) em escolas ou classes especiais implica impedir essa socialização benéfica para todos os alunos com e sem deficiência (s), sob a marca destrutiva da intolerância. As práticas segregacionistas surtiram efeitos esmagadores junto às pessoas com deficiência (s), às escolas e à sociedade em geral. Com a filosofia de que estariam em melhores condições e sob proteção em ambientes segregados, distanciados do resto da sociedade, só se fortaleceram os preconceitos, os estigmas e os mecanismos de defesa (mito das classes “homogêneas").

Em tese, a proposta de inclusão oferece a todos os alunos uma oportunidade mais justa ao satisfazer às necessidades educacionais via sistema da educação regular. Embora haja obstáculos à implementação da escola inclusiva, a história mais recente já evidencia que temos avançado rumo a uma educação mais ampla, com a prática de vivências cada vez mais inclusivas. A ampliação do sistema inclusivo tem proporcionado o distanciamento da segregação, transformando a educação especial e a educação regular em um sistema único, estabelecendo passos para o fim gradual de práticas educacionais excludentes, que sempre estiveram presentes também na escola dita regular. Na vivência inclusiva, os alunos aprendem a respeitar as diferenças e os direitos de todos como cidadãos, de modo a elucidar que o exer- 
cício da cidadania começa a ocorrer a partir do respeito ao espaço a que todos tenham acesso. Desse modo, corroboramos o estabelecido na Declaração de Salamanca (UNESCO, 1994).

O movimento chamado "inclusão" no âmbito da educação especial visa quebrar as barreiras existentes entre pessoas com deficiências e a sociedade pela interação via escolarização dos alunos com deficiência (s) com alunos ditos “normais". Abrange o trabalho de alunos com deficiência (s) e alunos ditos "normais"; alunos com deficiência (s), escola regular e educador; alunos com deficiência (s), escola e família. A inclusão reforça o exercício da concepção de que as diferenças devem ser aceitas e respeitadas, destituindo, sem dúvida, as experiências do passado.

Stainback e Stainback (1999) afirmam ser preciso destituir a imposição feita pelo sistema educacional de que alunos com deficiência (s) necessitam lutar pelo direito de participar da educação regular. É inadmissível que pesquisadores, estudiosos tenham que provar a competência e a capacidade dos alunos com deficiência (s), enquanto outros alunos têm passagem garantida, só por não carregarem o rótulo de "deficiente". Nenhum aluno deveria necessitar de um mero teste ou de comprovações de pesquisas, demonstrando competências e potenciais dos alunos com deficiência (s), para que possa ter acesso à educação regular. A escola é exemplo na sociedade, inclusive quando quebra tabus e regras preconceituosas, incluindo a todos, minando a sociedade com valores universais de respeito e cooperação, justiça e dignidade.

Os esforços de reestruturação do sistema educacional na perspectiva inclusiva têm conduzido a questionamentos que foram trabalhados no presente estudo, entre eles: Como as instituições segregativas e inclusivas têm vivenciado as relações com as pessoas com deficiência (s)? Como estão sendo vivenciadas as dificuldades que surgem no cotidiano escolar? Para a psicanálise, em geral, não admitimos e não temos noção das nossas próprias reações e em que estas se fundamentam. Frequentemente damos uma explicação meramente racional. E o que constantemente ocorre? A origem das reações, das atitudes e ações do sujeito está contida no inconsciente com uma carga emocional imensa. 0 nosso consciente é comandado o tempo todo pelo inconsciente (FREUD, 1926).

Os mecanismos de defesa emergem como proteção ao nosso eu; diante de uma pressão que gera ansiedade e tensão, o funcionamento psíquico busca uma solução carregada de mecanismos de defesa, como afirmam Fadiman \& Frager (1986) e Amaral (1994), a exemplo da negação, da superproteção e da projeção, que podem também emergir revestidos de preconceitos e estigmas, de acordo com Goffman, (1988). São exemplos das reações que o funcionamento psíquico opera para manter o equilíbrio intrapsíquico, eliminando a tensão, a ansiedade, a insegurança, o medo, a angústia etc., condutas defensivas emergentes no cotidiano dos sujeitos (GAY, 1999).

0 mecanismo psíquico funciona de tal forma que, diante de uma ameaça, tensão ou pressão, há uma predominância do emocional sobre o racional. Com isso, as relações estabelecidas estão imbuídas de relações transferenciais, ou seja: o indivíduo transfere para o outro relações estabelecidas outrora, de forma consciente ou, na maioria dos casos, inconscientemente. Essas relações estão mergulhadas nas emoções (raiva, medo, repulsa, tristeza, perda etc.), por sua vez, geradoras de ansiedade e angústia. Na experiência profissional cotidiana observam-se, frequentemente, pessoas ditas "normais" que acabam por gerar ações e comportamentos discriminatórios dirigidos a um alvo específico: as pessoas com deficiência (s). É o que demonstra Amaral (1994).

O sujeito busca uma maneira de se proteger ao fugir do problema, ansiedade que se defronta com 
duas saídas: enfrentar a realidade ou fugir do problema, o que implica encontrar, como válvula de escape, mecanismos de defesa como negação, superproteção e projeção, trabalhados na pesquisa em sua dimensão afetivo-emocional, considerando o universo emocional dos profissionais, pais e alunos frente à deficiência. Percebemos a relevância da atuação do inconsciente e nos questionamos: estão os profissionais e os pais conscientes de tal mecanismo?

\section{FUNDAMENTOS TEÓRICO-METODOLÓGICOS DA PESQUISA DE CAMPO}

Os dados obtidos foram analisados sob a iluminação das categorias: estigma, preconceito e mecanismos de defesa (negação, superproteção e projeção), abordadas teoricamente e reconstruídas no plano empírico. Tratou-se de pesquisa de campo, de caráter descritivo, com abordagem qualitativa, que aponta para o recrudescimento de mecanismos de excludência da educação brasileira, não obstante a proclamada política de educação inclusiva. Sua referência objetiva imediata são as relações interpessoais de educadores, gestores, pais e alunos que vivenciam esses processos, com as respectivas representações.

Fundamentamo-nos metodologicamente na concepção dialética da sociedade e de suas instituições para tentar decifrar a segregação e a inclusão escolar, desnudando a estrutura oculta das instituições educacionais e, dessa forma, construir um conhecimento que já se inicie pela resistência ao senso comum e aos estereótipos. Nosso pressuposto é o de que a realidade social dessas instituições é fruto da ação humana inserida numa totalidade concreta, sempre em movimento, marcada por contradições, assumindo uma atitude de distanciamento e estranhamento diante do conhecido, familiar ou daquilo que no cotidiano das instituições é tido, de certa maneira, como "natural". Tentamos inferir, a partir das evidências constatadas, sobre o grau de atuação do inconsciente, dos mecanismos de defesa (negação, superproteção e projeção) que emergem nas interações cotidianas dessas pessoas, dos estigmas e preconceitos de pais e professores, em relação às pes- soas com deficiência (s), de modo a caracterizar os respectivos cotidianos escolares nessas instituições.

Embora sem efetuar uma mesoabordagem às instituições, temos por premissa que a raiz do elevado grau de excludência no sistema educacional que se propõe a fazer a educação inclusiva, no âmbito das práticas institucionais, encontra-se na própria sociedade de classes, da qual o principal avalista é o Estado. Como reflexo dessa realidade nas instituições educacionais, constatamos que aí se confrontam forças do progresso humano com as forças conservadoras, o que evidencia a relevância deste estudo. Tratamos aqui da política de educação inclusiva assumida pelo governo brasileiro e da defesa concreta da educação como direito humano de todo cidadão, processo de socialização/apropriação da cultura, desenvolvimento e humanização pessoal e social. Verificamos que, na prática institucional, há uma explícita resistência dos agentes educativos ao processo de inclusão e uma persistência da segregação tradicionalmente arraigada na cultura da educação especial.

Apesar da pujante exclusão social nas décadas de 1980 e 1990, a revisão da literatura elucida que nesse período a sociedade foi, gradativamente, modificando-se, para aceitar as pessoas com deficiência (s), possibilitando o meio favorável para o desenvolvimento de suas potencialidades. A partir daí, emergiram as propostas de inclusão, limitadas, de início, à dicotomia deficientes versus normais, ensejando uma estruturação de aprendizagem cognitiva e emocional superior aos 
que se encontram nas escolas especiais (segregativas), uma vez que as pessoas com deficiência (s) que estão nesse processo segregativo pouco ou quase nada se têm modificado na direção da sua amplitude humana e cidadã (sua condição humana tem sido desconsiderada), o que é confirmado por Mantoan (1998).

Falamos das escolas especiais que tem, na prática, a proposta de adaptação do aluno com deficiência (s) para inseri-lo no meio e acabam por enfatizar suas incapacidades. Não percebem o potencial que ele possui para desenvolver-se, estigmatizando-o, conduzindo-o a um nível de simples adestramento das funções psicomotoras. A Psicologia já demonstrou que toda criança necessita, além da estimulação do ambiente familiar, de uma escola que estimule suas capacidades latentes, proporcione oportunidades de trocas significativas e desafios crescentes.

Os procedimentos metodológicos utilizados para investigar as práticas institucionais de vivência segregativa e/ou inclusiva, com foco em sujeitos com deficiência (s), a partir das relações interpessoais com pessoas ditas "normais", bem como pontuar as resistências que emergem nos respectivos contextos, levaram-nos à seguinte categorização na análise dos dados: Estigma, Preconceito e Mecanismos de Defesa (Negação, Superproteção e Projeção). Nessa perspectiva escolhemos o enfoque no cotidiano escolar para a análise dos efeitos segregativos e inclusivos, entendendo o cotidiano como um espaço em que se veicula a transmissão de valores e ideologias que emergem nas interações e contradições das relações sociais em que se estrutura a escola, sendo um lócus onde também se faz a história dos sujeitos e das instituições, com suas contradições.

Na busca das respostas aos questionamentos, escolhemos como técnica de abordagem a entrevista semiestruturada, por ser dotada de suficiente flexibilidade para que se estabeleçam as interações do entrevistador com os sujeitos, com as devidas adaptações. 0 método etnográfico, com seus pressupostos, foi a inspiração metodológica, razão pela qual ao lado das entrevistas desenvolvemos observações nas diferentes instituições abordadas, com a anuência prévia de todas as direções e docentes, mediante Termo de Consentimento Livre e Esclarecido. Optamos também por observações diretas e registros cursivos diante da especificidade do nosso objeto de estudo, os quais nos permitiram contato direto com as práticas e perspectivas dos sujeitos envolvidos na pesquisa e facilitaram a análise dos dados no confronto entre a linguagem falada verbal e a linguagem não verbal, confirmando-se o descrito por Ludke e André (1986).

As entrevistas com representantes de instituições que vivenciam o processo segregativo, bem como das que vivenciam o processo inclusivo, foram fundamentais para nortear a busca de respostas à questão básica da investigação: como essas instituições estabelecem as relações com os alunos com deficiência (s) e de que forma elas percebem os resultados, tanto da segregação quanto da inclusão? Nesse sentido, foram decisivas as entrevistas com os professores atuantes nas vivências segregativas e/ou inclusivas, uma vez que eles interagem diretamente com os alunos. Questionamos sobre possíveis dificuldades em seus desempenhos e no estabelecimento de relações com os alunos com deficiência (s), reunindo assim os fragmentos da vivência prática, analisando-os à luz das propostas teóricas e dos objetivos específicos da investigação.

A abordagem aos pais dos alunos com deficiência (s) realizou-se mediante o relato voluntário das experiências, o que nos permitiu a descoberta das suas expectativas da segregação e/ou da inclusão. Pela própria natureza da pesquisa, recolhemos também depoimentos de alunos com e sem deficiência (s). Através das entrevistas, ouvimos alguns alunos com deficiência (s): como eles vivenciam e percebem a sua realidade. Aos alunos ditos "normais" indagamos sobre seus contatos com as pessoas com deficiência (s). Ambos os tipos de aluno aqui destacados foram também observados em suas relações com os colegas, com os professores; as observações diretas ocorreram nas instituições de vivência segregativa e naquelas de vivência dita inclusiva, considerado o contexto sócio educacional em que estão inseridos. 
QUADRO 01 - População Abordada/Natureza das Instituições/ Funções dos Sujeitos

\begin{tabular}{|c|c|c|c|c|c|c|}
\hline \multirow{2}{*}{$\begin{array}{l}\text { NATUREZA } \\
\text { DA } \\
\text { INSTITUIÇÃO }\end{array}$} & \multirow{2}{*}{$\begin{array}{l}N^{\circ} \text { DE } \\
\text { INSTITUIÇO- } \\
\text { ES } \\
\text { SEGUNDO A } \\
\text { NATUREZA }\end{array}$} & \multicolumn{5}{|c|}{ SUJEITOS ABORDADOS } \\
\hline & & DIRETORES & $\begin{array}{l}\text { PROFESSO- } \\
\text { RES }\end{array}$ & $\begin{array}{l}\text { PAIS DE } \\
\text { ALUNOS C/ } \\
\text { DEFICIÊN- } \\
\text { CIA (S) }\end{array}$ & $\begin{array}{c}\text { ALUNOS C/ } \\
\text { DEFICI- } \\
\text { ÊNCIA (S) }\end{array}$ & $\begin{array}{c}\text { ALUNOS S/ } \\
\text { DEFICIÊN- } \\
\text { CIA (S) }\end{array}$ \\
\hline $\begin{array}{l}\text { Filantrópica } \\
\text { Segregativa }\end{array}$ & 02 & 02 & 01 & 04 & 03 & - \\
\hline $\begin{array}{l}\text { Pública } \\
\text { Segregativa e } \\
\text { Inclusiva }\end{array}$ & 02 & 02 & 04 & 02 & 02 & - \\
\hline $\begin{array}{l}\text { Privadas } \\
\text { Inclusivas }\end{array}$ & 03 & 02 & 07 & 02 & 04 & 01 \\
\hline Total & 07 & 06 & 12 & 08 & 09 & 01 \\
\hline
\end{tabular}

A população abordada foi constituída por trinta e seis (36) sujeitos, conforme Quadro 0. Tanto as instituições quanto os sujeitos abordados tiveram sua identificação preservada, sendo atribuídos códigos numéricos para as primeiras e códigos alfabéticos para as pessoas, respeitando-os através do anonimato, conforme respectivos Termos de Consentimento Livre e Esclarecido assinados.

Vê-se nesse Quadro que o universo da pesquisa constituiu-se de sete (7) instituições, nas quais entrevistamos um total de 6 diretores acerca do como trabalham com os alunos com deficiência (s) e quais as expectativas em relação a eles. Paralelamente, com seu consentimento explícito, observamos como cada instituição propõe o espaço para a educação (projeto pedagógico em curso), o que algumas instituições foram mais resistentes (Instituições 3 e 4). A Instituição 3 não permitiu as entrevistas com os alunos e determinou um professor para ser entrevistado. Já a Instituição 4 selecionou os professores e os alunos a serem ouvidos.
Foram 12 os professores entrevistados, também com explícita anuência, dentre os quais três trabalham com o processo da vivência segregativa e $9 \mathrm{com}$ o ensino inclusivo. A seleção dos professores ocorreu de acordo com a série dos alunos com deficiência (s) entrevistados. Dessa forma, entrevistamos o aluno e o professor que o acompanhava no seu desenvolvimento pedagógico. Durante as entrevistas com os professores, buscamos conhecer suas dificuldades docentes e como vivenciam o processo educacional em relação às pessoas com deficiência (s). Nesse processo de abordagem via entrevistas, oito mães foram ouvidas, dentre as quais duas tinham filhos com deficiência (s) matriculados na Instituição um; duas na Instituição cinco; duas na Instituição seis e duas na Instituição sete. Durante essas entrevistas, ouvimos a experiência dos pais em relação ao fato de terem um filho com deficiência (s), dentro de todo o contexto proposto da pesquisa e como estabelecem suas relações com seus filhos. A população abordada contemplou sujeitos de diferentes camadas sociais. 
Ainda foram entrevistados e observados nove alunos de ambos os sexos, com deficiência (s), entre crianças e adolescentes de 10 a 19 anos de idade, cursando séries variadas de $2^{\mathrm{a}} ; 5^{\mathrm{a}} ; 7^{\mathrm{a}}$ e $8^{\mathrm{a}}$ (cabe salientar que nesse período ainda não estava instituído o ensino fundamental de nove anos). A princípio, procuramos uniformizar a amostra em termos das séries cursadas pelos alunos. Contudo, algumas instituições não permitiram entrevistas com os alunos (como foi o caso da instituição 3) e outras ainda determinavam o aluno que seria entrevistado, a exemplo da instituição quatro, que não permitiu abertura para um maior contato, bem como impossibilitou um número maior de alunos entrevistados. Conseguimos, em contextos inclusivos, entrevistar apenas um (1) aluno sem deficiência (s).

As entrevistas foram realizadas através de conversas informais durante o recreio, das quais todos os alunos queriam participar. Somando-se a essas entrevistas, tivemos também as observações, que foram feitas nos contatos informais e na sala de aula. Defrontamo-nos claramente com as questões sociais e observamos como estão estabelecidas as relações no dia a dia dos alunos, entendendo que o homem participa na vida cotidiana com todos os aspectos de sua individualidade, de sua personalidade, emergindo, dessa forma, o estabelecimento de suas relações interpessoais.

As instituições abordadas seguem caracterizadas no Quadro 2, a partir das concepções pedagógicas identificadas na fase de coleta de dados. Regem-se por princípios teórico-práticos heterogêneos, diversificando-se desde as instituições que trabalham com o sócio interacionismo, como é o caso da Instituição cinco, até instituições indefinidas pela ausência de um planejamento, direcionamento educacional e pedagógico, em relação aos fundamentos da educação que desenvolvem, como é o caso das Instituições um, seis e sete. No Quadro três são mapeadas, por instituição, as categorias de análise que funcionaram também como critérios de seleção e interpretação do volumoso material obtido: estigmas, mecanismos de defesa (negação, superproteção e projeção) e preconceitos.

QUADRO 2 - Caracterização das Instituições Abordadas Segundo Representações dos Sujeitos

\begin{tabular}{|l|l|}
\hline \multicolumn{1}{|c|}{ IDENTIFICAÇÃO } & \multicolumn{1}{|c|}{ CARACTERIZAÇÃO PEDAGÓGICA } \\
\hline Instituição 1 & $\begin{array}{l}\text { Instituição filantrópica de proposta segregativa, porém } \\
\text { tem como objetivo a intervenção prática de inserção das } \\
\text { pessoas com deficiência (s) no mercado de trabalho. } \\
\text { Desenvolve trabalhos artesanais com os alunos, além } \\
\text { da parte pedagógica, envolvendo os pais. }\end{array}$ \\
\hline Instituição 2 & $\begin{array}{l}\text { Entidade pública estadual com proposta segregativa. } \\
\text { Afirma não seguir uma determinada linha filosófica ou } \\
\text { pedagógica e presta apoio aos professores que enfren- } \\
\text { tam as dificuldades dos alunos com deficiência (s) em } \\
\text { relação à aprendizagem. }\end{array}$ \\
\hline Instituição 3 & $\begin{array}{l}\text { Instituição privada com proposta inclusiva baseada nas } \\
\text { teorias construtivistas. Promove educação continuada } \\
\text { como capacitação para os professores, preparando-os } \\
\text { para a inclusão. }\end{array}$ \\
\hline
\end{tabular}




\begin{tabular}{|l|l|}
\hline Instituição 4 & $\begin{array}{l}\text { Instituição privada que tem a proposta de ensino inclu- } \\
\text { sivo, baseada nas teorias humanistas. }\end{array}$ \\
\hline Instituição 5 & $\begin{array}{l}\text { Instituição privada com vivência inclusiva, tendo como } \\
\text { pressuposto teórico e filosófico a teoria sócio interacio- } \\
\text { nista, priorizando o contexto sócio-histórico como tam- } \\
\text { bém a interação humana, não levando em consideração } \\
\text { o que a sociedade considera “normal" ou "patológico". }\end{array}$ \\
\hline Instituição 6 & $\begin{array}{l}\text { Instituição pública estadual que tem como proposta o } \\
\text { ensino segregativo em algumas séries (1a à 4a série) } \\
\text { e em outras séries propõe o ensino inclusivo (ensino } \\
\text { fundamental: } 5^{a} \text { à 8a série). Não adota qualquer linha } \\
\text { pedagógica. }\end{array}$ \\
\hline Instituição 7 & $\begin{array}{l}\text { Instituição filantrópica de vivência segregativa, sem } \\
\text { embasamento teórico. Volta-se, além da parte peda- } \\
\text { gógica, para o despertar e o desenvolver de alguma } \\
\text { habilidade nos alunos com deficiência (s). Para tanto, a } \\
\text { escola utiliza as oficinas de artesanato. }\end{array}$ \\
\hline FonTE: Entrevistas dos Diretores das Instituiçôes (2002)
\end{tabular}

QUADRO 3 - Instituições/Categorias de Análise

\begin{tabular}{|l|c|c|c|c|c|}
\hline \multirow{2}{*}{$\begin{array}{l}\text { INSTITUIÇÕES } \\
\text { EDUCACIONAIS }\end{array}$} & \multicolumn{5}{|c|}{ CATEGORIAS DE ANÁLISE } \\
\cline { 2 - 5 } & ESTIGMA & \multicolumn{3}{|c|}{ MECANISMOS DE DEFESA } & \multirow{2}{*}{ PRECONCEITO } \\
\cline { 3 - 6 } & $\mathrm{PROJEÇÃO}$ & NEGAÇÃO & SUPERPROTEÇÃo & $\mathrm{x}$ \\
\hline $\begin{array}{l}\text { Instituição 1 } \\
\text { Filantrópica Segregativa }\end{array}$ & $\mathrm{x}$ & $\begin{array}{c}\text { Não } \\
\text { registrado }\end{array}$ & $\mathrm{x}$ & $\begin{array}{c}\text { Não } \\
\text { registrado }\end{array}$ & $\mathrm{x}$ \\
\hline $\begin{array}{l}\text { Instituição 2 } \\
\text { Pública Estadual Segregativa }\end{array}$ & $\mathrm{x}$ & $\mathrm{x}$ & $\mathrm{x}$ & $\begin{array}{c}\text { Não } \\
\text { registrado }\end{array}$ & $\mathrm{x}$ \\
\hline $\begin{array}{l}\text { Instituição 3 } \\
\text { Privada } \\
\text { Proposta Inclusiva }\end{array}$ & $\mathrm{x}$ & $\mathrm{x}$ & $\mathrm{x}$ & $\mathrm{x}$ & $\mathrm{x}$ \\
\hline $\begin{array}{l}\text { Instituição 4 } \\
\text { Privada } \\
\text { Proposta Inclusiva }\end{array}$ & & & & & \\
\hline
\end{tabular}




\begin{tabular}{|l|c|c|c|c|c|}
\hline $\begin{array}{l}\text { Instituição 5 } \\
\text { Privada } \\
\text { Proposta Inclusiva }\end{array}$ & $\begin{array}{c}\text { Não } \\
\text { registrado }\end{array}$ & $\mathrm{x}$ & $\begin{array}{c}\text { Não } \\
\text { registrado }\end{array}$ & $\mathrm{x}$ \\
\hline $\begin{array}{l}\text { Instituição 6 } \\
\text { Pública Estadual } \\
\text { Proposta Segregativa e Inclu- } \\
\text { Siva }\end{array}$ & $\mathrm{x}$ & $\mathrm{x}$ & $\mathrm{x}$ & $\begin{array}{c}\text { Não } \\
\text { registrado }\end{array}$ & $\mathrm{x}$ \\
\hline $\begin{array}{l}\text { Instituição 7 } \\
\begin{array}{l}\text { Filantrópica } \\
\text { Proposta Segregativa }\end{array}\end{array} \quad \begin{array}{c}\text { Não } \\
\text { registrado }\end{array}$ & $\begin{array}{c}\text { Não } \\
\text { registrado }\end{array}$ & $\mathrm{x}$ & $\mathrm{x}$ & $\mathrm{x}$ \\
\hline
\end{tabular}

O Quadro 3 traz à tona a realidade contraditória da problemática estudada. Todas as cinco categorias de análise foram registradas em duas instituições (1 e 4), a primeira de natureza filantrópica, com proposta segregativa e a segunda, da rede privada, com proposta inclusiva, respectivamente. Por outro lado, destacamos que as instituições que tiveram menos registros dessas categorias (2, 5 e 7 ) integram as redes pública estadual, privada e filantrópica de ensino, respectivamente, sendo que a instituição cinco desenvolve uma proposta pedagógica inclusiva. Nas demais instituições (3 e 6) as categorias incidem em blocos de quatro das cinco aqui reconstruídas.

Sua leitura na vertical elucida ser o preconceito a categoria que marcou presença em todas as instituições abordadas (100\%), independentemente da rede de subordinação administrativa e do tipo de proposta educacional (segregativa ou inclusiva). É importante apurar a análise qualitativa de modo a identificar o segmento e o modelo pedagógico, que manifestaram maior carga de preconceitos, até para reorientar as políticas e/ou respectivas estratégias. Esse dado revela o peso dos preconceitos incorporados ao longo dos anos em relação às pessoas com deficiência (s) - como endemoniados, doentes, loucos, incômodos cristãos, incapazes, vidas não dignas etc. - cristaliza- dos e repassados de geração para geração, que tem acompanhado a evolução de paradigmas nessa área: desde a segregação, avançando parcialmente pela via da integração e aproximando-se hoje da inclusão.

A categoria menos registrada foi a superproteção, mecanismo de defesa que se concentrou nos depoimentos de pais de alunos com deficiência (s), alcançando $57,1 \%$ das instituições. Em nenhum caso percebemos a superproteção nas direções ou no corpo docente. 0 mecanismo de defesa da negação incidiu em $85,7 \%$ das instituições. As demais categorias, o estigma e o mecanismo de defesa da projeção, registraram-se em $71,4 \%$ das instituições abordadas. Essa incidência das categorias estudadas nas práticas e representações dos agentes educacionais já é um forte indicativo do grau de desafio que a política de inclusão enfrenta. Esse é seu pano de fundo que lhe desafia continuamente.

Os detalhes de cada instituição educacional trabalhada, com recortes de falas e observações dos sujeitos, que ajudam a desnudar o enigma da inclusão na sociedade excludente, apontando os estigmas, os mecanismos de defesa e os preconceitos impregnados na cultura institucional, serão objeto de outra comunicação. 


\section{CONSIDERACÕ̃ES FINAIS}

Os sujeitos abordados revelaram suas percepções e ideias, assim como lembranças, com suas implicações, dando um contributo ímpar ao estudo; daí nosso integral respeito a cada um, a garantia ética do absoluto anonimato e o compromisso da devolutiva. Trabalhamos com sua subjetividade, com a clareza de que a cada vez que trazemos à memória determinadas representações, novas sensações emergem no momento presente, com a invasão do passado atuando sobre as percepções atuais. Entendemos também que as lembranças associam-se à memória coletiva que se acumula em toda a trajetória de evolução paradigmática da sociedade.

Como pesquisadoras, sofremos rebuliço em nossas convicções a respeito da inclusão enquanto tentávamos proporcionar aos sujeitos uma releitura de suas práticas via atuais representações; como professoras que somos, reconhecíamo-nos continuamente no objeto de estudo. A relação dialética sujeito-objeto na pesquisa foi intensa: muito ouvimos e vimos nas relações intraescolares; aprendemos na prática sobre a política de inclusão em curso. Nossas inferências são tentativas de respostas provisórias, construídas na intersubjetividade de pesquisadores e sujeitos da investigação, com suas respectivas circunstâncias, considerado o contexto social determinado pelo excludente modo capitalista de produção da existência.

Nas instituições, além das barreiras arquitetônicas, curriculares e atitudinais à efetiva inclusão dos alunos com deficiência (s), caracteriza as relações que aí se desenvolvem um ambiente, aparentemente enigmático e pesado, que logo se desvela como marcado por angústia, insegurança e medo, sentimentos que encobrem a resistência à inclusão e os preconceitos, impregnados em todos os segmentos, em alguns casos de modo explícito, tanto no seio de propostas segregativas quanto nas inclusivas, o que, em princípio, parece paradoxal.
Essa situação está evidenciada no Quadro 3: as cinco categorias de análise que se apresentam como restritivas à efetividade da política de educação inclusiva incidiram todas elas tanto em uma instituição segregativa quanto em uma instituição inclusiva, a primeira filantrópica e a segunda privada (instituições 1 e 4). Constatamos a incidência de quatro (4) dessas categorias na instituição pública estadual em que conviviam as propostas segregativa e inclusiva (instituição 6), assim como em uma escola inclusiva da rede particular (instituição 3). As que tiveram menos registros dessas restrições (três) foram: uma instituição inclusiva da rede particular de ensino (instituição 5), uma escola pública estadual segregativa (instituição 2) e uma instituição filantrópica segregativa (instituição 6).

Quando considerados esses dados apenas na perspectiva quantitativa, a perplexidade poderá emergir, 0 que só se esclarece com a retomada da análise qualitativa, considerada cada instituição de per si, cada segmento da comunidade escolar em particular e a natureza dos preconceitos expostos. Ao olhar apurado desnuda-se, no emaranhado de interações, um saldo positivo favorável à Instituição cinco, da rede particular de ensino, com proposta inclusiva.

Sendo a inclusão declarada política pública do governo federal e estadual, em tese, representa a vontade do Estado (incluindo a sociedade civil, segundo visão ampliada de Estado), traduz-se em programas de ação governamental, é informada por valores e ideias neoliberais ou liberais modernas da cidadania que se dirigem aos públicos escolares junto aos quais é implementada pelos profissionais da educação, imersos em densa gama de preconceitos, estigmas e mecanismos de defesa. A rede pública não se destacou positivamente, nem mesmo na Instituição 6 em que convivem as duas propostas antagônicas: segregativa e inclusiva. 
Enveredamos no campo da educação inclusiva que, historicamente, tem sido negada à população, talvez pelo ângulo mais sensível: a convivência de alunos com e sem deficiência (s). Trouxemos à tona o silenciado dessa política, a economia de afetos que na prática a sustenta, a abundância de preconceitos, estigmas e estereótipos, visando sua humanização e uma nova dinâmica pedagógica. Que possamos todos repensar e readministrar nossas atitudes em relação ao outro, em nome da genericidade que nos une, independentemente das particularidades que nos diferenciam!

Nesse sentido, a atual política de inclusão defronta-se com dois desafios nas instituições: a carga ideológica (uma vez que sua proposta é desenvolver-se com a manutenção das relações instituídas sob a égide da exclusão) e os mecanismos psíquicos do inconsciente presentes nos pais e em cada agente educacional (não devidamente trabalhados na formação docente). A formação de professores, tanto a inicial quanto a continuada, não tem contemplado o estudo do inconsciente, dos mecanismos de defesa e da identidade. Gestores, professores e pais têm dificuldades de lidar com seu próprio inconsciente e de trabalhar com uma pedagogia inclusiva, no que a constituição de equipes multidisciplinares nas unidades escolares poderá ajudar a assumir esse desafio.

A pesquisa desenvolvida nessas sete instituições que propõem vivências segregativas e/ou inclusivas aponta para a premente necessidade de ampliação da conscientização de diretores, professores, pais de alunos, enfim, de toda a sociedade, a partir desse saber recém-construído sob estigmas, preconceitos e mecanismos de defesa (negação, superproteção e projeção) que emergem como resistências nas relações interpessoais das ditas pessoas "normais" para com aquelas que são diferentes, especialmente quando apresentam deficiência (s).

Sabemos que trazemos aqui à tona reflexões sobre uma crise real, que se acirra no campo pedagógico e psicológico, alcançando o universo subterrâneo do inconsciente, que precede e vem acompanhando a implantação da política pública de educação inclusiva. Enquanto persistirem na sociedade paradigmas preconceituosos, o lugar das pessoas com deficiência (s) é e será sempre de aprisionamento e isolamento como ser humano, logo, um lugar à margem. De fato, para a educação e vida digna de pessoas com deficiência (s), impõe-se que a sociedade as respeite e supere o estado de alienação a que lhes tem reduzido.

Evidenciou-se que os estigmas, preconceitos e mecanismos de defesa (negação, superproteção e projeção) são categorias manipuladas pelos envolvidos no processo educacional segregativo e/ou inclusivo, de modo que as instituições escolares impedem o desenvolvimento das potencialidades das pessoas com deficiência (s), negligenciando na formação humana e no aperfeiçoamento da função social da escola, no sentido de garantir a ampla socialização da cultura acumulada, com educação de qualidade para todos, seja qual for sua condição física, mental, socioeconômica, racial e de credo religioso.

Os estigmas estiveram presentes em $71,4 \%$ das instituições abordadas; os $28,6^{\circ}$ da exceção a essa regra referem-se às instituições 5 e 7. A instituição 5 propõe vivência inclusiva, desenvolve um trabalho coerente com sua proposta de inserção do aluno com e sem deficiência (s) no mesmo processo educacional. Seus representantes afirmam dar apoio aos professores e a todos os envolvidos no movimento inclusivo. As resistências que emergem no dia a dia escolar, nesse contexto, são trabalhadas e enfrentadas como componentes da quebra de preconceitos. A não camuflagem é importante no confronto das resistências a essas questões, sobre as quais os profissionais sentiram-se à vontade para falar, apontando as dificuldades.

Na Instituição cinco é nítida a revolução que progressivamente faz, avançando na quebra de paradigmas: os alunos com e sem deficiência (s) encontram-se nos intervalos das aulas conversando normalmente, brincando, sem a menor intervenção de qualquer adul- 
to; nas salas de aulas há um entrosamento entre todos. Ficou patente que a inclusão não é um processo acabado e pronto, mas que se (re) estrutura no cotidiano escolar. Para tanto, a instituição precisa estar verdadeiramente aberta, disposta e atenta para enfrentar esse cotidiano efetivando as quebras de paradigmas estigmatizantes.

Nas instituições um, dois, seis e sete, que vivenciam a segregação, $57,1 \%$ da população alcançada, foram percebidas as questões dos estigmas, mecanismos de defesa e preconceitos de forma mais acentuada, embora o critério de estigma não tenha sido registrado na instituição sete. Não constatamos práticas homogêneas, nem pedagogias delineadas; há diferenças no lidar com a segregação; a Instituição 1 apresenta certo descaso, desde o espaço físico em que se encontra, quase que abandonado, até as questões pedagógicas, sem um planejamento e uma preparação do trabalho que se desenvolve com os alunos, além do fato de o professor não ter uma formação adequada para essa modalidade de educação.

Nessa mesma linha da segregação, vimos que a Instituição sete tem proposta mais clara nos seus procedimentos, embora sem um planejamento e sem clareza de uma linha teórica. Preocupa-se com o desenvolvimento de habilidades dos alunos com deficiência (s) nas oficinas de arte. Os pais se envolvem e participam do processo de aquisição de materiais, não só para essas oficinas como também para a reforma da escola, reforçando os pleitos institucionais de colaboração junto às empresas locais, promovendo festas para arrecadar fundos para a instituição e, até mesmo, quando necessário, fazem suas próprias doações. Essa parceria mostrou-se positiva para os alunos que se apresentam visivelmente confortados com o envolvimento dos pais nos problemas da escola.

Já a Instituição dois tem uma forma planejada, própria, de vivenciar a segregação; a direção pontua que não segue qualquer teórico da aprendizagem e sua resistência à inclusão é notória. Os alunos são vistos como detentores de déficits enfatizados pelo diagnóstico, o que, por sua vez, impede o desenvolvimento da inteligência dos alunos com deficiência (s), em detrimento mesmo da zona de desenvolvimento proximal.

A instituição seis, que propõe vivências segregativas e inclusivas, funciona como palco de conflitos, angústias e resistências por parte de todos, desde a direção até os professores, alcançando também os alunos segmento no seio do qual se instala um mal estar entre os colegas com e sem deficiência (s). Nela, vimos os estigmas, mecanismos de defesa e preconceitos emergirem de todos os "cantos" e não percebemos a intenção de trabalhá-los em qualquer dos segmentos envolvidos. Os professores não demonstraram clareza da sua função social e pedagógica, mostraram-se resistentes a todo tipo de trabalho com os alunos com deficiência (s). Alguns deles revelaram certa agressividade no falar, relatando não desejar desenvolver a relação de ensino e de aprendizagem ou o contato com esses alunos, por considerá-los limitados e deficientes. Verificamos que esses alunos agrupam-se entre si e isolam-se do restante do grupo. A instituição enfatiza suas limitações, negando-lhes o espaço para o desenvolvimento.

A Instituição três, que propõe vivências inclusivas, apresentou-se confusa, insegura e desprovida do conhecimento teórico-prático necessário à inclusão. Encontramos aí professores angustiados e sem qualquer acompanhamento, supervisão ou apoio no desenvolvimento do seu trabalho. Nessa Instituição, os estigmas, os preconceitos e os mecanismos de defesa emergem de forma camuflada, por trás da proposta inclusiva. Também apresentou-se-nos alheia ao processo inclusivo a Instituição quatro, embora dita inclusiva. Os professores se contradiziam nas suas próprias falas, revelando suas angústias; nem a direção da escola demonstrou acreditar no processo de desenvolvimento das pessoas com deficiência (s).

Dessa forma constatamos que a vivência segregativa, no período pesquisado (2002 a 2004), não surtia efeito salutar para as pessoas com deficiência, como 
observamos nas Instituições um, dois, seis e sete. Por outro lado, vimos que não é suficiente dizer que a proposta é inclusiva para que os efeitos mostrem-se superiores qualitativamente: é preciso conhecer e dominar procedimentos, acreditar na inclusão, investir no apoio e supervisão de todos os que fazem parte da instituição escolar. Não se faz política pública sem acompanhamento e controle não só do Estado como da sociedade civil. Política pública não é um rótulo nem se faz mecanicamente, mesmo quando cercada de legislação e pactos internacionais. Caso a escola não se proponha à mudança de princípios e valores estigmatizantes, como vimos em embrião nas instituições três e quatro, entramos no faz-de-conta: faz-de-conta que educamos, faz-de-conta que ensinamos, faz-de-conta que incluímos; faz-de-conta que vivemos!

A falta de clareza das instituições educacionais, tanto segregativas quanto inclusivas, em relação à proposta pedagógica em curso, os estigmas, preconceitos e mecanismos de defesa que emergiram o tempo todo nas relações interpessoais, seja no dia a dia da escola seja no cotidiano da vida familiar, impõem que os responsáveis pela política pública da inclusão trabalhem novos paradigmas, de modo a desencadear efetiva reforma do pensamento. Urge uma revolução na forma de pensar para que a prática excludente seja superada, inclusive aquela que penetra as instituições ditas inclusivas.
Ousamos concluir que, para superar a excludência no seio da política de educação inclusiva, que se desenvolve sob a hegemonia da ideologia calcada na competição, produção material e exploração de muitos por poucos, urge a ação organizada da sociedade civil para retomar o controle dessas práticas, cobrando a aplicação das políticas inclusivas, radicalizando seus próprios discursos. Assim, os diferentes espaços educativos (incluindo-se não só as escolas, mas a família, o trabalho, a igreja, a mídia e outros) sofrerão efetivas demandas para repensarem e reconstruírem relações interpessoais salutares, a partir do princípio básico de aceitação do outro como um ser especial, independentemente de sua compleição física. Nesse panorama identifica-se o papel da formação inicial e continuada docente.

Finalizamos denunciando a manipulação, o domínio das instituições que detêm o poder com padrões de normalidade, e afirmando a esperança no educador do futuro, protagonista de um novo estilo de pensamento e atitudes nas relações intrapessoais, superando rótulos e indiferenças em favor da educação inclusiva. Esta é a reforma de pensamento e ação de que necessitamos neste século: o reconhecimento da condição humana, da luta concreta pela superação da cultura do sofrimento em favor da felicidade de cada homem. 


\section{REFERÊNCIAS}

AMARAL, L. A. Pensar a diferença/deficiência. Brasília: Coordenadoria Nacional Para Integração da Pessoa Portadora de Deficiência - Corde; 1994.

CASTRO, Jorge Abrahão de. Evolução e desigualdade na educação brasileira. In: Educação \& Sociedade. Campinas, São Paulo: vol. 30, n. 108, p. 673-697, out. 2009. Disponível em: http://www.cedes.unicamp.br.

FADIMAN, James \& FRAGER, Robert. Teorias da personalidade. Coordenação da tradução Odette de Godoy Pinheiro; trad. Camila Pedral Sampaio, Sybil Safdié: Habra, 1986.

FREUD, Sigmund. Inibições, sintomas e ansiedade. Vol. XX (1925/1926). In: Obras completas de Sigmund Freud. Rio de Janeiro: Ed. Imago, 1995.

FREUD, Sigmund. Lapso da fala. Sobre a psicopatologia da vida cotidiana. Vol. VI (1901). In: Obras completas de Sigmund Freud. Rio de Janeiro: Ed. Imago, 1995.

FREUD, Sigmund. 0 futuro de uma ilusão. Vol. XXI (1927). In: Obras completas de Sigmund Freud. Rio de Janeiro: Ed. Imago, 1995.

FREUD, Sigmund. O mal-estar na civilização. Vol. XXI (1929-1930). In: Obras completas de Sigmund Freud. Rio de Janeiro: Imago, 1995.

FREUD, Sigmund. Psicologia de grupo e análise de
Ego. Vol. XVIII (1921). In: Obras completas de Sigmund Freud. Rio de Janeiro: Imago, 1995.

FREUD, Sigmund. Sobre o narcisismo: uma introdução. Vol. XIV (1914). In: Obras completas de Sigmund Freud. Rio de Janeiro: Imago, 1995.

GAY, Peter. Freud: uma vida para o nosso tempo. Trad. Denise Bottmam. São Paulo: Companhia das Letras, 1999.

GOFFMAN, Erving. Estigma: notas sobre a manipulação da identidade deteriorada. Rio de Janeiro: Ed. Guanabara; -1988.

LUDKE, M.; ANDRÉ, M. E. D. A. Pesquisa em educação: abordagens qualitativas. São Paulo: EPUI, 1986.

MANTOAN, Maria Teresa Eglér. Ensino inclusivo: educação de (qualidade) para todos. In: Revista Integração. p. 29-32. Ano 8, n 20. 1998.

MORIN, Edgar. Os sete saberes necessários à educação do futuro. Cortez: Brasília/ UNESCO, 2001.

STAINBACK, Susan Bray; STAINBACK, William. Inclusão: um guia para educadores. Trad. Magda França Lopes. Porto Alegre-RS: Artes Médicas; 1999.

UNESCO. Declaração de Salamanca. Conferência Mundial Sobre as Necessidades Educativas Especiais. Espanha, 1994. 
I Doutora em Educação pela Universidade de São Paulo (USP). Professora do Programa de Pós-Graduação em Educação da Universidade Tiradentes. Líder do Grupo de Pesquisa GPGFOP/PPED/Unit/CNPq e Coordenadora Institucional do Projeto Transeja do Observatório de Educação da Capes/Unit. Atualmente faz o Estágio Pós-Doutoral Sênior pela Capes junto à Universidade de Lisboa - Portugal. E-mail: adaaugustaeduc@gmail.com.br

II Psicóloga pela Universidade Federal de Sergipe. Professora da Educação Básica da Secretaria de Estado da Educação de Sergipe. Pós-graduada em Psicanálise pela UFS e em Psicologia Social pelo Centro Universitário de João Pessoa-PB. Pesquisadora do Grupo de Pesquisa GPGFOP/PPED/Unit/ Aceito em: 3 dez. 2012 CNPq. E-mail: auxiliadora.souza@bol.com.br 